\title{
Painful ankle swelling
}

\author{
Annu Chopra • Andrew J. Grainger • \\ Emma L. Rowbotham
}

Published online: 2 December 2014

(C) ISS 2014

\section{Question}

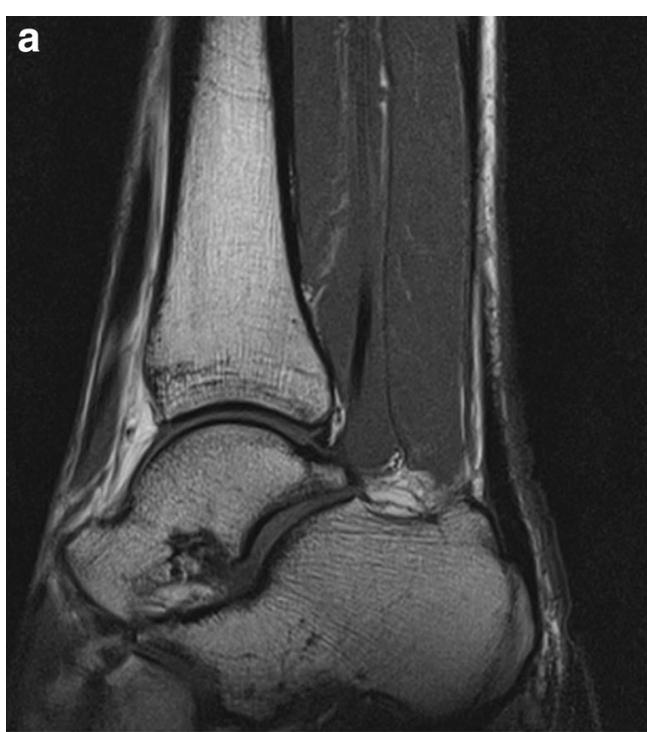

A normally fit and well 33 year old elite athlete, with acute onset of pain and swelling around the region of the Achilles tendon whilst running, was referred for an MRI by his physiotherapist (See Figs. 1 and 2).

The diagnosis can be found at doi: 10.1007/s00256-014-2073-5

A. Chopra $(\square)$

Sheffield Teaching Hospitals NHS Foundation Trust, Northern General Hospital, Herries Road, Sheffield S5 7AU, UK e-mail: Annu.chopra@sth.nhs.uk

A. J. Grainger · E. L. Rowbotham Leeds Teaching Hospitals NHS Foundation Trust, Chapel Allerton Hospital, Leeds LS7 4SA, UK

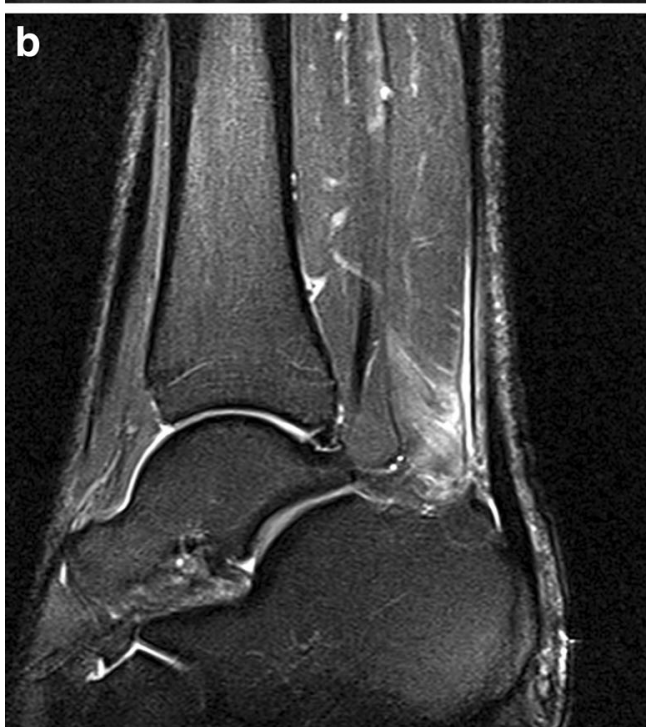

Fig. 1 a. T1 Sagittal right ankle. b. T2 Fat sat sagittal right ankle 

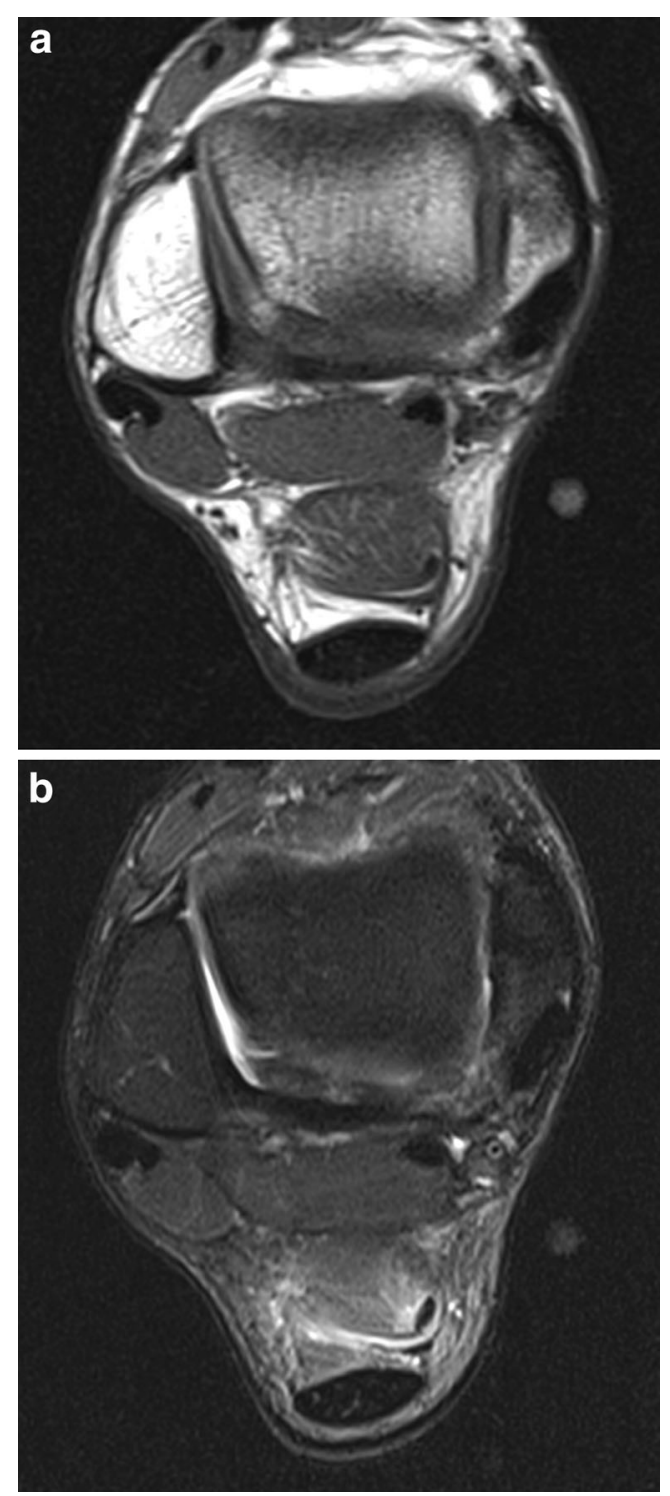

Fig. 2 a. T1 Axial right ankle. b. T2 Fat sat axial right ankle 